\title{
Researchers' Workshop: A New Approach for Literacy Learning in School Libraries
}

\author{
Barbara McNeil \\ Assistant Professor \\ Faculty of Education, University of Regina \\ Canada
}

\begin{abstract}
This paper presents a model of literacy learning and research in school libraries that is inclusive and responsive to the needs of diverse learners. It draws on four educational theoretical frameworks: sociocultural theory, the pedagogy of care, readers' workshop, and critical pedagogy. This practical model consists of four important phases. They include social interaction, the building and maintenance of caring relationships with students, guided assistance, and students' right to return for assistance. The paper will discuss the practical applications of the model and how it contributed to higher levels of literacy achievement for a variety of students.
\end{abstract}

School libraries, critical literacy, research approach

\section{Introduction}

Working with adolescent learners was one of the joys of teaching and learning in secondary school libraries. For me, a substantial part of that joy came from the approach I used with students to co-conduct research and inquiry into topics that were of interest to them. Inspired by the pedagogy of Nancie Atwell (1987; 1998), I used a workshop approach to searching and inquiry and called it researchers' workshop. Similar to Atwell's readers' and writers' workshops that use a combination of whole class, minilessons, small group, and individual instruction over a continuous period of time, researchers' workshop explicitly incorporates the Vygotskian (1978) socio-cultural concepts of social interaction, shared jointlearning, guided apprenticeship, and a gradual release of ownership of the learning activity. Along with the preceding, there are two other important features of researchers' workshop: it is firmly grounded in Noddings $(1996 ; 1999 ; 2005$ relational pedagogy of caring and in Freirean (1970) critical theory.

In what follows I will tell the story of researchers' workshop as I lived it. In telling the story, I describe the genesis and components of the researchers' workshop. My purpose in sharing the story is to inform and inspire teacher-librarians to seek alternative directions in the practice of school librarianship.

\section{The genesis of researchers' workshop}

Researchers' workshop grew out of my pedagogical restlessness, growing critical consciousness, and an ethical commitment to interact more fully with marginalized, struggling readers, writers, and researchers. The marginalized students were often from cultural, linguistic, racial, and economically disadvantaged groups and I wanted to have greater connectedness with them in the school library. The ideas of Nancie Atwell (1987) had informed my pedagogical 
practices when I was a full-time classroom teacher and the publication of her new book in 1998 led me to examine how I could incorporate workshop approaches to research and inquiry in the school library. Soon after I began experimenting with researchers' workshop, I began to link it to the Vygotskian ideas that I was learning about in my graduate studies. When seen from a Vygotskian viewpoint, the school library is a sociocultural site where particular forms of social practices such as locating, assessing, reading, and using, and critiquing information takes place. Within a Vygotskian framework such learning is conceived as a shared-joint process between adults and children interacting in a responsive social context. Although I believed in, and emphasized the social interactional component of my work with students, planned guided lessons, and provided guided apprenticeship in research, I knew I had to go further to develop even greater connectedness with students.

I also knew that a more critical perspective was needed since it was clear to me that the school library was not a neutral, depoliticized, sociocultural site that fostered neutral (natural) cultural and social practices. I turned to critical pedagogy because it is

fundamentally committed to the development and evolvement of a culture of schooling that supports the empowerment of culturally marginalized and economically disenfranchised students. By so doing, this pedagogical perspective seeks to help transform those classroom structures and practices that perpetuate undemocratic life (Darder, Baltodano \& Torres, 2003).

As a product of the dominant society, I believe that the secondary school library tends to privilege the ways of valuing, knowing, thinking, and doing of mainstream students. The school library's proclivity toward maintenance of the status quo troubled me and I wanted to trouble and disrupt it.

The sociocultural, sociohistorical, political site in which I work is one characterized by over four hundred of years of colonial oppression (multiple forms of domination and subordination) whose impact on schooling still resonates strongly today among the Onkwehonwe - original peoples - and all those who call Saskatchewan home (Alfred, 2005). It is clear to me that resistance to colonial oppression started as soon as the colonizers began to show their true intentions and used their cunning, stronger military and economic power to take over the lands and suppress the Onkwehonwe. This resistance continues today in society and unavoidably in schools. Therefore, the critical, conscious, and ethical practice of school librarianship in such a context is not neutral.

"Critical education contends that, contrary to the traditional view, schools actually work against the class interests of those students who are most politically and economically vulnerable in society" (Darder, Baltodano \& Torres, 2003). Critical education — critical school librarianship acknowledges the impact of the legacies of colonialism (e.g., poverty due to socio-economic exclusion, discrimination, and educational disadvantage) and seeks to disrupt it. For me, being critical in this context meant that my practice of school librarianship had to be oriented toward developing caring, respectful, and "dialogic" relationships with all students - especially those from subordinated groups - so as to work alongside them to create a more ethical, robust and socially just society. 
In addition, I opted for change in my pedagogical practices because I had reached the point in my personal and professional life where I wanted to be more explicit and activist in my desire to transform the world in order to make it more equitable and just. Also fanning the winds of change for me was my growing dissatisfaction with what I perceived to be the skewed Discourse (Gee, 1996) - the technical rationalist language of school librarianship (Doherty, 2005/2006).

Though I was a major beneficiary of the profession's fixation on "information," "information literacy skills," and "technology" (American Association of School Librarians (AASL) \& Association for Educational Communications and Technology (AECT), 1998; Bleakley \& Carrigan, 1994; Eisenberg \& Berkowitz, 1990; Kuhlthau, 1995) it troubled me. It troubled me because I did not see an explicit, commensurate or equal professional focus on the relational - the caring relationship that must be developed and sustained between teacherlibrarians and students. I saw a preoccupation with methods, a ("methods fetish") that was not accompanied by pedagogical structures that spoke to the day-to-day reality, struggles, concerns, and dreams of subordinated students Bartolomé (2003 p. 410).

I did not see sufficient focus on the role of teacher-librarians' in critically addressing the needs of the increasing numbers of racial, cultural, economically disadvantaged, and linguistic minority students who were not doing well in school literacy and other areas critical to success in schools and life. My desire to bolster the theoretical and practical foundations of researchers' workshop in addition to my disaffection with the functionalist and technocratic orientation of the profession led to the (un) covering of the work of Atwell $(1987 ; 1998)$, Noddings $(1999 ; 2005)$ and Freire (1970) in order to overtly bring a socially conscious and greater moral dimension to my work in researchers' workshop. In the final analysis researchers' workshop grew out of my growing humanistic/humanizing educational philosophy.

\section{Researchers' workshop}

According to the Canadian Oxford Dictionary, a workshop is "a meeting for concerted discussion and practical work on a particular subject, in which a group of people share their knowledge and experience" (2004, p. 1795). My conception of view (1998) that a "workshop is student-centered in the sense that individuals' rigorous pursuit of their ideas is the primary content of the course." (p. 71). Similar to Atwell's workshops, researchers' workshop places strong emphasis on knowledge acquisition and construction through use of a variety of sociocultural tools which includes (but is not limited to) reading and writing, and extends such emphasis to researching (e.g., planning, retrieving, processing, creating, sharing, evaluating, and reflecting on the process (Learning Resource Council \& Alberta Teachers Association, 2004)). In addition, I believed it was imperative to add a social justice component to and taking social action researchers' workshop.

Therefore, in researchers' workshop, the teacher-librarian pays particular attention to reading and writing school English in the various content areas and to helping students develop and strengthen those practices, as he/she teaches and guides students through research processes. The starting point for all transactions in researchers' workshop is listening to students, understanding their historical realities and recognizing and valuing the sociocultural resources and literacies they bring to research and inquiry. 
I worked hard to make researchers' workshop an embodied sociocultural experience that valued the unique identities of students - their multiple literacies - and thus went far beyond pen, paper, and PowerPoint presentations. Like Atwell, I have journeyed to the realization that workshop approaches best accommodate the needs of adolescents, invite their independence, challenge them to grow," and promote deep understanding of the interrelatedness and complexities of the topics they select for inquiry and for action (Atwell, 1987; 1998).

\section{The Structure/Framework}

Researchers' workshop is constructed on the premise that learning takes time and that literacy learning through research and inquiry requires sustained contact with students. Fortunately, I began my journey with researchers' workshop in a school district in which block scheduling, in one hour periods, is the status quo for all secondary schools.

Block scheduling provided me with the time I needed to work holistically with students on research and inquiry. Along with that, much of the success I had in using a workshop approach to do research and inquiry in school libraries was dependent on the enormous assistance I received from the library assistants with whom I worked.

Within the framework of researchers' workshop, I typically invited classroom teachers to sign up for an hour per day over a five-day period. Although, we did not always use the five hours allocated for research, I blocked off five days for the teachers with whom I collaborated on research projects to ensure that there would be enough time to work with students in meaningful ways. Researchers' workshops operate on the principle that we cannot overtly teach all that we know about research or inquiry; some of the knowledge is acquired through enculturationimmersion in research activities over extended periods of time with more knowledgeable others in school libraries and elsewhere (Gee, 1996, Vygotsky, 1978).

In researchers' workshop, the school library is a jointly shared "territory" (Atwell, 1998) where the teacher-librarian and students work together closely and collaboratively along-side each other as they develop social and cultural practices that involves, decoding, inquiring, and encoding a variety of texts. Researchers' workshop is a way of working with students, a way of doing research that eschews 'quick fixes' and 'on the run' approaches; it is undergirded by the heart-felt conviction that students matter and that research is a messy, time-consuming, at times exhilarating, and at other times anxiety-producing process.

\section{Literacy in researchers' workshop}

In researchers' workshop, I work with the sociocultural understanding that the actions we take when we engage in research and inquiry (e. g., talking, reading, writing, locating, retrieving, analyzing, and reflecting on text types and information) build on and extend social practices and therefore see literacy as plural-literacies - rather than as singular-literacy. This understanding is informed by Gee's (1996) view that literacy is related to primary and secondary Discourses.

Gee states that, 
A Discourse is a socially accepted association among ways of using language, other symbolic expressions, and 'artifacts', of thinking, feeling, believing, valuing, and acting that can be used to identify oneself as a member of a socially meaningful group or 'social network', or to signal (that one is playing) a socially meaningful 'role' (p. 131).

Gee argues that everyone has primary a Discourse and that it serves as a foundation for future acquisition and learning of secondary Discourses (p.141). Furthermore, Gee points out that "any socially useful definition of literacy must be couched in terms of these notions of primary and secondary Discourses" (p. 143). Such a view of literacy leads Gee to point out that "literacy is always plural: literacies (there are many secondary Discourses, and we all have some and fail to have others)." This sociocultural view suggests that there are many culturally informed ways of speaking, reading, writing, analyzing, reflecting, and responding to texts. Thus, in the rich, heterogeneous school library contexts, in which many of us work, it is important to acknowledge that learners are diverse, come from different Discourse communities and have different forms of literacies that may be different from traditional school literacy.

In researchers' workshop, I recognize that students from "marginal social groups often struggle to get a handle on the culture" of school libraries and therefore I act in overt ways (e.g., caring, offering more time and guided assistance through talk, modeling, and demonstration) to help them navigate and become more fluent in those discourses (Gee, 1996, Lankshear \& Knobel, 2007). Researchers' workshop is an approach that provides students extended opportunities to be immersed in and acquire school languages/discourses as they engage in research and inquiry.

\section{Connectedness}

I believe that increasingly, when it comes to research and other forms of engagement in school libraries, students are asking, pushing on the question of, "where am I in this story, in this picture," and this, as Hunsberger (2007) points out, is a call for "connectedness" (p. 420). The connectedness of which Hunsberger speaks is about broadening our definition of literacy so that it is sociocritical, in order to achieve "a clear, deliberate, and intentional focus upon "connectedness" between the reader and the text" so that the school literacy experiences of students are more directly linked to their cultural, social, and material realities (p. 421).

Connectedness is important for the students with whom I work because as Hunsberger points out, "the poverty that encircles [many of] their lives creates a constant barrage of experiences that we seldom discuss or read about in the texts we choose for our literacy instruction" (p. 421). Tatum (2005) expresses a similar idea when he describes the kind of literacy instruction that made a difference in his life. He states,

My teachers understood that my life experiences and how I responded to these experiences mattered. They understood that the texts they placed before me had to address some of the psychological and emotional scarring that results from the day-to-day experiences of being black, male, and poor in America. My teachers wanted to help me develop an identity that would be useful outside the walls of my school (p. 25).

In school libraries, Researchers' workshop is a pedagogical approach that I reached for in order to connect readers to texts and to critically connect research to the lived lives of students as a way of offering possibilities for liberation (Hunsberger, 2007; Freire, 1970). The primary 
concern of researchers' workshop is not strategy and skill instruction (Tatum, 2005). The research that we do in researchers' workshop is explicitly linked to the development of critical consciousness, where students, through the research topics and projects they pursue, can "critically recognize" the causes of their oppression (e.g., poverty and the socio-economic structures that give rise to it, racism, bullying, the absence of language classes for English Language learners, eating disorders, self-cutting, sexual harassment, homophobia, hypermasculinity, exclusions, suspensions, and expulsions from school etc.). Thus, critical consciousness is conducting research in such a way that we learn to "perceive social, political, and economic contradictions, and to take action against the oppressive elements of reality" (Freire, 1970, 19).

\section{A Pedagogy of care}

The environment that best supports researchers' workshop is a school library or media center that is a place of care, love, and trust. Noddings (2005) artfully articulated the indispensable, fundamental role of care in education. She explains that

a caring relation is, in its most basic form, a connection or encounter between two human beings-a carer and a recipient of care, or cared-for. In order for the relation to be properly called caring, both parties must contribute to it in characteristic ways. A failure on the part of either carer or cared-for blocks completion of caring and, although there may still be a relation - that is, an encounter or connection in which each party feels something toward the other-it is not a caring relation (p. 15).

Noddings' maintains that caring is not an individual virtue or attribute (though it requires individuals to have the virtues and capacities to care) since caring "recognizes the part played by the cared-for" (p. 21). It is an ethic of relation. In writing about caring relations and encounters in education, Noddings (2005) points out that "No matter how hard teachers try to care, if the caring is not received by students, the claim "they don't care" has validity" (p. 15).

Thus, "it is not enough to hear the teacher's claim to care," it must be apparent to and lived by students - they must perceive themselves to be cared for by the teacher. Caring is a way of being in relation, not a set of specific behaviors" (Noddings, 2005, p. 17). My work with students in researchers' workshop is guided foremost by the value I place on guiding and teaching in a relational way (Noddings, 2005). I want adolescent researchers to know that I care about them, that I know that they care about the topics they select for inquiry, and that I am available to tease out issues with them as they proceed along the meandering, messy, crooked, frustrating, and yes, exhilarating path of research.

When high school students see, wave at, run, greet, and oftentimes hug me in hallways, in shopping malls, at concerts, in record stores, and/or at community gatherings, I do not believe it is primarily because I have taught them the skills or "standards" associated with information literacy (AASL \& AECT, 1998; Asselin, Branch \& Oberg, 2003). Rather, I am convinced that the students' responsiveness toward me is ignited by the care I offered to them, and the responsive relationships I developed with them over time, through researchers' workshop, in the school library. As Noddings (2005) suggests, “... subject matter cannot carry itself”; much, much more is needed. 
For me, the current that carries subject matter (e.g., the contextually-based teaching of information literacy skills for research, the exploration of ideology in an author's work, the examination of race, class and gender in texts, the unpacking of the concept of censorship) in the school library is the sustained care that is offered to students in each exchange and each transaction. Like Noddings, (2005) I believe that the "living other is more important than any theory" and articulated that belief in a particular way. Researchers' workshop as I practiced it provided the framework for enacting an ethic and pedagogy of care (Noddings, 2005) in a deep and rich way. Thus, the most important aspect of conducting meaningful inquiry and/or successful research in researchers' workshop is the caring relationship between the student and the teacher-librarian.

\section{A critical approach to caring and inquiry}

While the model of researchers' workshop that is introduced and developed here draws heavily on Atwell's (1987, 1998) readers and writers workshops, Vygotskian concepts of interaction and guided assistance, Noddings" "ethic of care" and relational pedagogy, it seeks to go much further. My vision of researchers' workshop incorporates the Freirean (1970) radical pedagogy of humanization aimed at engendering democratic, progressive social transformation for social justice and freedom. Researchers' workshop is a way for me and for other progressive teacher-librarians to enact "critical intervention" through, "praxis"- "the action and reflection of men upon their world in order to transform it" (Freire, 1970, p.66). Researchers' workshop provides for a deeper, richer approach to research/inquiry and its transformative possibilities. Through researchers' workshop we can "practice co-intentional education" wherein, according to Freire (1970),

[t]eachers and students, co-intent on reality, and thereby, are both Subjects, not only in the task of unveiling that reality, and thereby coming to know it critically, but in the task of re-creating that knowledge. As they attain this knowledge of reality through common reflection and action, they discover themselves as its permanent re-creators" (p. 56).

In the school library, researchers' workshop is "dialogic," co-intentional, "problemposing" education that is the anti-thesis of what Freire describes as "banking education" in which the "the students are the depositories and the teacher is the depositor." In the alienating, undemocratic and dis-empowering model of "banking" education, "the scope of action allowed to the students extends only as far as receiving, filing, and storing deposits" (p. 58).

Researchers' workshop eschews the practice of "banking education"; it is concerned with inquiry and as Freire suggests,

"...apart from inquiry, apart from the praxis, men cannot be truly human. Knowledge emerges only through invention and re-invention, through the restless, impatient, continuing, hopeful inquiry men purse in the world, with the world, and with each other" (p. 58).

Guided by the belief that all students bring a rich mixture of history, knowledge, experiences, skills, interests, queries, and dreams that are indispensable to the "critical inquiry of reality" (the area of greatest interest to many secondary students), teacher-librarians operating in the framework of researchers' workshop need to see themselves and their students as teachers 
and as students (Freire, 1970) simultaneously. In researchers' workshop, students are searchers whose "ontological vocation is humanization" (p. 62). Students' requests for books, journals, assistance with online databases, and the assistance of a co-researcher/co-inquirer are first steps that can be indicative of their desire and drive to know more, for richer understanding, and to go further along the path of their full humanization. Researcher's workshop allows the teacherlibrarian to enter a lateral "humanist" and transformative partnership with students and in so doing propels them towards the goal off full humanization. I believe that the possibilities for the re-creation of reality, social transformation, and humanization are enhanced through researchers' workshop.

\section{A culture of collaboration}

The relational pedagogy that underpins researchers' workshop is essential to building a culture of collaboration with students and teachers. Researchers' workshop requires collaboration. In her book on Collaboration and the school library media specialist, Doll (2005) explains that "collaboration is the ultimate level of involvement" between a school library media specialist [teacher-librarian] and classroom teachers as they work together to plan and evaluate "lessons, units, and the curriculum itself" (p. 8).

\section{Access to students}

My experience tells me that it is vital for a teacher-librarian to build positive and caring collaborative relationships with teachers in order to have the kind of sustained access to students that is needed for researchers' workshop. By having coherent and consistent access to students - that is, meaningful periods of time in which to engage in quality research - the teacher-librarian is able to actualize care in dialogic and critical ways (Freire, 1970).

\section{Search space}

Along with the need to have sustained and meaningful access to students over an extended period of time for the purposes of conducting research inquiry, an important feature of a researchers' workshop that is specifically oriented towards adolescents, is the need for, and, use of what I call a search space. Search space is a theoretical construct that refers to carving out, setting aside of a concrete physical space wherein an individual student (or group of students) can render explicit, through dialogue (or other means) his thinking and reflection on the topic he wishes to excavate, understand and interrogate with the teacher-librarian.

Also, I theorized search space, as a psycho-social construct wherein teacher-librarians are intentional in creating mental space and giving meaningful attention to the needs of adolescents as embodied, complex beings who are shaped by culture, gender, history, race, sexuality, emotionality, and economics.

It is not to be wondered at, that a site such as search space is necessary; research is often an iterative, complex, idiosyncratic, unwieldy process that needs patient transactions and distillations. Meaningful inquiry with adolescent students cannot be conducted 'on the run;' it cannot be done at the library desk when there are groups of students lined up, waiting to be served. In order to actively demonstrate to students that they are valuable and cared for, and to simultaneously respond to the anxiety-driven vulnerability that young researchers usually exhibit 
at the beginning of a "dialogic" research journey, it is important to have a physical space that allows the student and the teacher-librarian to have caring and critical transactions about research. The psycho-social aspect of search space permits the student and the teacher-librarian to set out on their journey by clearing a cognitive space, a mental or head space that allows thinking and reflection on a topic of research or inquiry.

It is in search space that developing or novice researchers formulate their questions, choose words, and take risks in exploring topics before they are shared publicly. For some students this may be short period and for others a longer period, but whatever the individual need of the student, it can be accommodated by researchers' workshop. By its very design, researcher's workshop is structured to enable teacher-librarians to transact in caring and dialogic ways with students in light of their individual interest, needs, and competencies, linguistic, social, and cultural situations.

\section{Search talk}

Search talk is "dialogic" in the Freirean sense of the word and is therefore egalitarian in nature (Bartlett, 2005); teacher-librarian and student are learners together. The search talk of researchers' workshop is not authoritarian. Similar to reading and writing workshops researchers' workshop uses a conference approach. Search talk is talk about research, talk about the particular discourses of research, talk about the subject of inquiry, talk about what students would like to know, talk about why a particular topic was chosen by the student and how it connects to their past, present and future imagined lives. Search talk occurs before, during, and after a research project. This purposeful talk not only helps to clarify the student's as well as the teachers' thinking, it helps to foster oracy_oral language development (especially for English Language Learners and other minority language students). Search talk builds and extends the vocabularies of students and where possible and practical (this is often), we use dictionaries thesauri, and glossaries as much as possible to support our talk.

The thread that knits the fabric of search talk involves more than Noddings' (2005) concept of caring, it rests on the teacher librarian's articulation of the Freirean concept of humanization and the necessary examination of social realities in critical ways in order to name them, and change them. Search talk is based on conversations not lectures, problem-posing, questioning, experimenting with and testing words and different search strategies and techniques. Search talk is not a quick answer to a reference question and the need to support the information literacy development of students; it is much more. Search talk is about responding to students in caring and critical ways that involve thought, conversation, and action to make the world a better place.

\section{The Provision of Guided Assistance}

The provision of guided assistance in researchers' workshop is rooted in Vygotsky's (1978) sociocultural, sociohistorical theory that asserts that "human learning presupposes a specific social nature..." and that children internalize cultural forms of behaviour and solve problems in conjunction with more knowledgeable others (adults and peers). In researchers' workshop, guided assistance is explicitly offered to students from the beginning to the end point 
of their research and the door is never closed so that students can accelerate their participation and learning in a caring and supportive way.

The humanist, equity agenda that I used in researchers' workshop made me mindful of the differences that exist among students and led me to take what Gutiérrez and Rogoff (2003) describe as a "cultural-historical approach" to research where learning is conceived as a "process occurring within ongoing activity, and not divided into separate characteristics of individuals and contexts" (p. 20). The cultural-historical approach involved "knowing about the individual histories" and some "valued cultural practices" of the groups the students belong to so that I could orient the instruction and guidance I provided to meet the particular needs of each student (Gutiérrez \& Rogoff, 2003).

\section{Students' right of return}

The right of return refers to students' right to seek guided assistance from the teacherlibrarian as part of an open-ended process of caring, valuing, thinking, and acting as culturalhistorical actors in researchers' workshop. In terms of what transpired on a day to day basis in the school library, the right of return spoke of my philosophy and fervently held belief about my availability to students. It helped me to liberate students from being hesitant and from expressing apologies for returning for assistance, for needing more of my time, for getting additional support. The right of return created space for welcoming and working with vulnerable students and could be operationalized before, during, and/or at the formal end of the school day.

The open-endedness of researchers' workshop is rooted in the Freirean (1970) idea that the world is not yet fully made. By emphasizing the right of return, I sought to illustrate to students that the world is in a continuous process of being made and that human beings still needed solutions to the problems of social injustice and this exhorts and allows each of usstudents and teachers alike - to be social dreamers and actors in order to create a better world.. With this vision, the door on research is never fully closed, understandings are never complete, knowledge and wisdom are not exhaustible; the great books/texts have not yet all been created, and the greatest individual and collective social acts of compassion and liberation from oppression have yet to be realized.

\section{Conclusion}

My story of researchers' workshop is one that documents my evolution as I grappled for more pedagogically responsive and critical ways of working with students in school libraries. The process has been not been a linear or uncomplicated one; it has been fraught with tensions, setbacks, anxieties, questions, and challenges from students, peers, and administrators.

Nonetheless, through researchers' workshop, I found an approach that allowed me to provide the caring, guided assistance my students needed, to build on their repertoires of practice in advancing literacy through research, and to collaborate more fully and meaningfully with teaching colleagues and support staff. In addition, researchers' workshop has made it possible for me to co-conduct research with students that focus on social and political issues that are of importance to them, their communities, and the world. It is through researchers' workshop that 
the students and I have come to frame curriculum as a "metaphor for the lives we want to live and the people we want to be" (Boomer \& Boomer, 1999).

\section{References}

Alberta Learning. (2004). Focus on inquiry: A teacher's guide to implementing inquiry- based learning. Edmonton, AB: Alberta Learning. Learning Resources Council of Alberta \& Alberta Teachers' Association.

Alfred, T. A. (2005). Wasáse: Indigenous pathways of action and freedom. Peterborough, ON: Broadview Press. American Association of School Librarians \& Association for Educational Communications and Technology. (1998). Information power: Buildingpartnerships for learning. Chicago: American Library Association.

Asselin, M., Branch, J. L., \& Oberg, D. (Eds.) (2003). Achieving information literacy: Standards for school library programs in Canada. Ottawa, ON: The Canadian School Library Association and The Association for Teacher-librarianship in Canada.

Atwell, N. (1998). In the middle: New understandings about writing, reading, and learning ( $2^{\text {nd }}$ edition). Portsmouth, NH: Boynton/Cook Publishers.

Atwell, N. (1987). In the middle: writing, reading, and learning with adolescents. Portsmouth, NH: Boynton/Cook Publishers.

Barber K., (2004). Canadian oxford dictionary (2nd edition). Don Mills, ON: Oxford University Press.

Bartlett, L. (2005). Dialogue, knowledge, and teacher-student relations: Freirean pedagogy in theory and practice. Comparative Education Review; August 2005, 49, 3.

Bartolomé, L. I. (2003). "Beyond the methods fetish: Toward a humanizing pedagogy. In Antonia Darder, Marta Baltodano \& Rodolfo D. Torres, The critical pedagogy reader (pp. 408-429). New York: RoutledgeFalmer.

Berger, K. S. (2005). The developing person: Through childhood and adolescence. New York: Worth Publishers.

Bleakley, A., \& J. L. Carigan. (1994). Resource-based learning activities: Information literacy for high school students. Chicago, IL: American Library Association.

Bomer, R. \& Bomer, K. (2001). For a better world: Reading and writing for social action. Portsmouth, NH: Heinemann.

Darder, A. Baltodano \& Torres, R. D. (2003). Critical pedagogy: An introduction. In Antonia Darder, Marta Baltodano \& Rodolfo D. Torres, The critical pedagogy reader (pp.1-21). New York: RoutledgeFalmer.

Doherty, J. J. (2005-2006). Towards self-reflection in librarianship: What is praxis? Progressive Librarian, 26, Winter 2005-2006, 1-8, http;//libr.org/pl/26_Doherty.html.

Doll, C. A. (2005). Collaboration and the school library media specialist. Toronto, ON: The Scarecrow Press, Inc.

Durrance, J. C., Fisher, K. E. with Hinton, M. B. (2005). How libraries and librarians help: A guide to identifying user-centered outcomes. Chicago, IL: American Library Association.

Eisenberg, M. B., \& R. E. Berkowitz. Information problem-solving: The big six skills approach to library and information skills instruction. Norwood, N. J.: Ablex.

Feldman, R. S. (2003). Development across the life span ( $3^{\text {rd }}$ edition). Upper Saddle River, NJ: Prentice Hall.

Freire, P. (1970). Pedagogy of the oppressed. New York: Continuum.

Gee, J. P. (1996). Social linguistics and literacies: Ideology in discourses ( $2^{\text {nd }}$ edition). New York: RoutlegeFalmer.

Gordon, S., Benner P., \& Noddings, N. (1996). Caregiving: Readings in knowledge, practice, ethics and politics, Philadelphia, PA: University of Pennsylvania Press.

Gutiérrez, K. D. (2008). Developing a sociocultural literacy in the third space. Reading Research Quarterly, 43, 2 , 149-163.

Gutiérrez, K. D. \& Rogoff, B. (2003). Cultural ways of learning: Individual traits or Repertoires of practice. Educational Researcher, 32, 5, 19-24.

Hunsberger, P. (2007). "Where am I?” A call for “connectedness" in literacy. Reading Research Quarterly, 42, 3, $420-423$.

Kearney, C. A. (2000). Curriculum partner: Redefining the role of the library media specialist. Westport, CT: Greenwood Press.

Kuhlthau, C. (2004). Seeking meaning: A process approach to library and information services ( $2^{\text {nd }}$ edition). Westport, CT: Libraries Unlimited.

Knobel, M. \& C. Lankshear (Eds.). (2007). Sampling "the New" in new literacies. In A new literacies sampler, 
Colin Lankshear \& Michele Knobel, (pp. 1-24). New York: Peter Lang.

Noddings, N. (2005). The challenge to care in schools: An alternative approach to education. New York: Teachers' College Press.

Noddings, N. (1999). Care, justice, and equity. In Michael S. Katz, Nel Noddings \& Kenneth A. Strike (Eds.), Justice and caring: The search for common ground in education, (pp. 1-20). New York: Teachers College Press.

Noddings, N. (1996). The cared for. In Suzanne Gordon, Patricia Benner \& Nel Noddings, Caregiving: Readings in knowledge, practice, ethics, and politics, (pp. 21-39). Philadelphia, PA: University of Pennsylvania Press.

Peterson, R. L. (1979). A place of caring and celebration: The school media center. Chicago, IL: American Association of School Librarians \& American Library Association.

Tatum, A. (2005). Teaching reading to black adolescent males: Closing the gap. Portland, ME: Stenhouse Publishers.

Vygotsky, L. S. (1978). Mind in society: The development of higher psychological processes. Cambridge, MA. Harvard University Press.

U. S. Department of Education. (2002). No child left behind: A desktop reference. Jessup, MD: U. S. Department of Education.

\section{Biographical Note}

Dr. Barbara McNeil is an Assistant Professor at the University of Regina where she teaches courses in reading and children's literature. Dr. McNeil's dissertation focused on transience and literacy. She has a Master of Library Science degree (MLS) from the University of Toronto and extensive experience in secondary and elementary school libraries. Dr. McNeil worked as a library consultant for seven years and has made numerous presentations to teacher-librarian and teacher audiences across Canada.

\section{Statement of Originality}

I certify that this paper is based on my original research and was conceived and written by me and has not been published elsewhere. All information and ideas from others is referenced. 